\title{
A Discrete Mathematical Modeling and Optimal Control of the Electoral Behavior with regard to a Political Party
}

\author{
Omar Balatif $\left(\mathbb{D},{ }^{1}\right.$ Abderrahim Labzai $\left(\mathbb{D},{ }^{2}\right.$ and Mostafa Rachik ${ }^{2}$ \\ ${ }^{1}$ Mathematical Engineering Team (INMA), Department of Mathematics, Faculty of Sciences El Jadida, \\ Chouaib Doukkali University, El Jadida, Morocco \\ ${ }^{2}$ Laboratory of Analysis Modeling and Simulation, Department of Mathematics and Computer Science, \\ Faculty of Sciences Ben M'Sik, Hassan II University Mohammedia, Sidi Othman, Casablanca, Morocco \\ Correspondence should be addressed to Omar Balatif; balatif.maths@gmail.com
}

Received 3 July 2018; Revised 6 October 2018; Accepted 14 October 2018; Published 5 November 2018

Academic Editor: Rigoberto Medina

Copyright ( $\odot 2018$ Omar Balatif et al. This is an open access article distributed under the Creative Commons Attribution License, which permits unrestricted use, distribution, and reproduction in any medium, provided the original work is properly cited.

In this work, we propose a discrete mathematical model that describes the dynamics of citizens who have the right to vote and their electoral behavior with regard to a political party during an awareness program or an electoral campaign. Also, we propose an optimal strategy for an awareness program or an election campaign that helps politicians to distinguish between different categories of voters in order to increase the participation rate in the electoral process and obtain the greatest possible number of votes with a minimal effort. Pontryagin's Maximum Principle, in discrete time, is used to characterize the optimal controls and the optimality system is solved by an iterative method. The numerical simulation is carried out using Matlab. Consequently, the obtained results confirm the performance of the optimization strategy.

\section{Introduction}

Political participation is one of the most important foundations of modern democracy in democratic countries. One of the most important aspects of political participation is the electoral process which makes the citizen a key player in the political decision-making process in the country. An election is a decision-making process by which a population chooses an individual to hold formal office. This is the usual mechanism by which democracy fills offices in the legislature and parliament. Faced with this crucial importance of the elections for the democratic process, numerous studies and researches have been conducted on the elections and the electoral behavior of the citizens. These studies are marked by three major research schools [1]: the sociological model, often identified as the School of Columbia with the main reference to the Applied Bureau of Social Research of Columbia University and whose work began with the publication of the book The People's Choice [2], focuses on the influences of social factors. The psychosocial model, also identified as the School of Michigan, which has its major reference in the work of Campbell, Converse, Miller, and Shanks [3], The
New American Voter, assumes that party identification is the main factor behind the behavior of voters. The rational choice theory, also referred to as a model of economic voting or even as the School of Rochester and whose landmark work is the work of Anthony Downs [4], An Economic Theory of Democracy, puts emphasis on variables such as rationality, choice, uncertainty, and information. Studies and research on the subject of elections are still ongoing to the present time (For example, [3, 5-11]). Also, mathematical modeling has been widely used to study different topics concerning the electoral processes and the dynamics of political systems (For example, [12-15]).

The main objective of political parties is to obtain political power to contribute to the reform of the country through a political program. Therefore, all political parties need to identify a plan to attract voters and obtain as many electoral votes as possible, taking into consideration means and resources, which are always "time, money, and human resources."

In this work, we propose a mathematical model that describes the dynamics of citizens who have the right to vote and their electoral behavior with regard to a political 
party. Also, we propose an optimal strategy for an election campaign or an awareness program that helps politicians to distinguish between different categories of voters which we have divided in our model into six compartments (potential electors, electors, temporary abstainers, permanent abstainers, voters for the political party, and voters against the political party) in order to increase the participation rate in the electoral process and obtain the greatest possible number of votes with a minimal effort.

To achieve these objectives, we applied the theory of optimal control for our proposed model. The theory of optimal control and the analysis of dynamic systems are a field of current research that continues to arouse the interest of scientists. It has been widely used in different fields such as engineering, biology, mechanics, medicine, robotics, and biomedicine. The aim of this theory is to model processes that evolve over time and to study their behaviors. This study makes it possible, among other things, to predict the behavior of the system and to control it in order to get the desired results.

In the theory of control of dynamic systems, there are two kinds of mathematical dynamic systems: the continuous time models described by differential equations and the discrete-time models described by difference equations. The continuous-time models have been widely investigated in many articles (for example, [16-20]). However, it is noted that, in recent years, more and more attention has been paid to the discrete-time models (see, [21-26] and the references cited therein). The reasons are as follows: first, the statistic data is collected at discrete times (day, week, month, or year). So it is more direct, more convenient, and more accurate to describe the phenomena by using the discrete-time models than the continuous-time models. Second, the use of discretetime models may avoid some mathematical complexities such as the choice of a function space and regularity of the solution. Then, the numerical exploration of discrete-time models is rather straightforward and therefore can be easily implemented by nonmathematicians.

The paper is organized as follows. In Section 2, we present our discrete mathematical model that describes the dynamics of citizens who have the right to vote and their electoral behavior with regard to a political party. In Section 3, we present the optimal control problem for the proposed model where we give some results concerning the existence of the optimal controls and we characterize these optimal controls using Pontryagin's Maximum Principle in discrete time. Numerical simulations are given in Section 4. Finally, we conclude the paper in Section 5.

\section{A Mathematical Model}

We consider a discrete mathematical model $P E A^{t} A^{p} V^{f} V^{a}$ that describes the dynamics of citizens who have the right to vote and their electoral behavior with regard to a political party. We divide the population denoted by $N$ into six compartments.

The potential electors $(P)$ are those who are entitled to participate in the elections. The class of potential electors is increased by the recruitment of individuals into the compartment $P$ at a rate $\Lambda$. It is assumed that potential electors can acquire abstainer behavior (and become the boycotts of the elections) via effective contacts with abstainers of the elections at a rate $\beta$. In other words, it is assumed that the acquisition of an abstainer behavior is analogous to acquiring disease infection. Although not considered in this study, other factors such as economic and social conditions can lead to the abstention of the elections. Also, potential elector can register in the electoral lists due to the contact with individual registrants at a rate $\alpha$ who have convinced him/her of the importance of participating in the elections. Therefore, potential electors become electors. Finally, potential electors suffer natural death (at a rate $\mu$ ).

The electors $(E)$ are those who are registered in the electoral lists and wish to vote in the elections. The compartment of electors is increased, at a rate $\alpha$, when potential electors register in electoral lists via effective contacts with the electors. The population is decreased when electors acquire abstainer behavior due to the contact with temporary abstainers of the elections at a rate $\delta$. It is decreased by natural death (at the rate $\mu$ ) and when electors move to vote (at a rate $\gamma)$ and become voters.

The temporary abstainers $\left(A^{t}\right)$ are those who have a hesitant position of abstaining the elections or the electors whose, sometimes, preoccupations or working conditions do not allow them to go voting and, thus, their participation in elections is not permanent. The population of temporary abstainers is increased by the potential electors (at a rate $\beta$ ) by a fraction $\sigma$, also, when the electors or individual voters, via effective contacts with temporary abstainers, change their attitude towards participation in the elections or their preoccupations or working conditions do not allow them to go voting. It is decreased by natural death (at the rate $\mu$ ) and reversion to voting (at rates $a$ and $b$ ).

The permanent abstainers $\left(A^{p}\right)$ are the individuals who have a consistent position of boycotting elections. The population of permanent abstainers is increased by the potential electors (at a rate $\beta$ ) by a fraction $1-\sigma$ and decreased by natural death (at the rate $\mu$ ).

The voters for the political party $\left(V^{f}\right)$ are the population of voters for the political party which is increased when electors move to vote for it due to the contact with the voters for the political party at a rate $\gamma$ by a fraction $\theta$ and when the temporary abstainers become voters via effective contacts with the voters at a rate $a$ and also when voters against the political party turn to vote for it due to the contact with voters for the political party at a rate $e$. The population is decreased by natural death (at the rate $\mu$ ) and by reversion to voting against political party (at the rate $f$ ) or abstaining the elections temporarily (at the rate $b$ ).

The voters against the political party $\left(V^{a}\right)$ are the population of voters against the political party which is increased when electors move to vote against it (at a rate $\gamma$ ) by a fraction $1-\theta$ and when the temporary abstainers become voters (at a rate $c$ ) and also when voters for the political party turn to vote against it (at a rate $f$ ). The population is decreased by natural death (at the rate $\mu$ ) and by reversion to vote for political party (at the rate $e$ ) or abstaining the elections temporarily (at the rate $d$ ). 


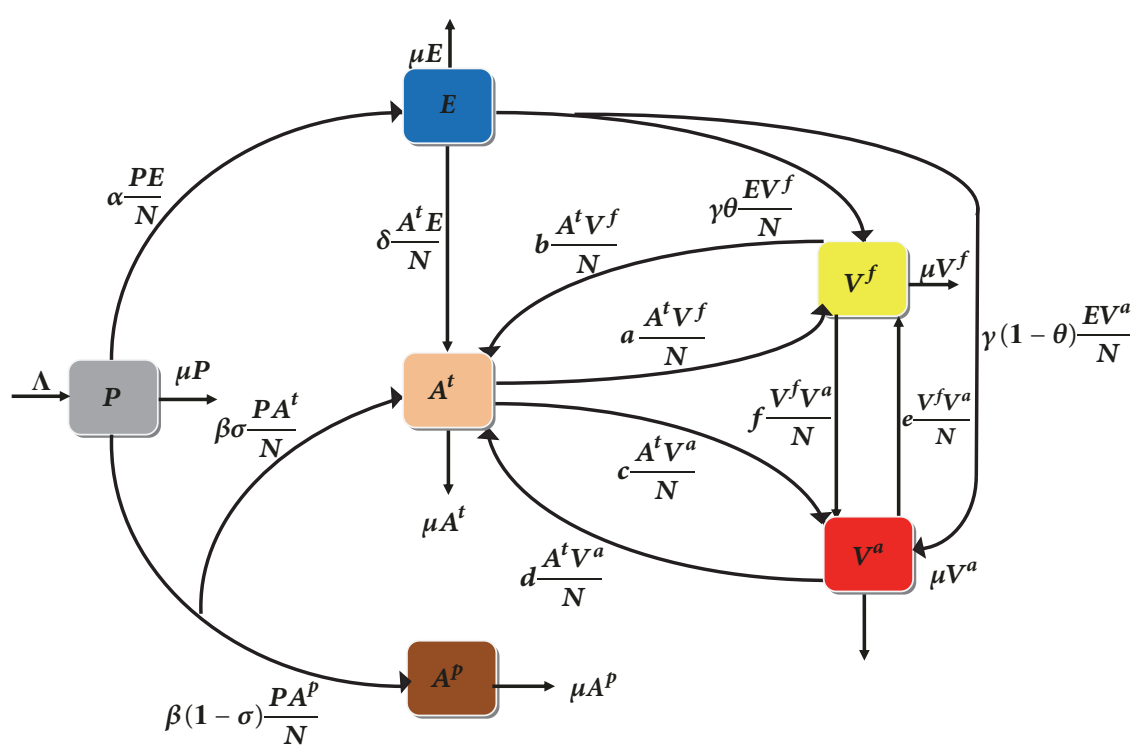

Figure 1

The variables $P_{i}, E_{i}, A_{i}^{t}, A_{i}^{p}, V_{i}^{f}$, and $V_{i}^{a}$ are the numbers of the individuals in the six classes at time $i$, respectively. The unit of $i$ can correspond to periods, phases, or years. It depends on the frequency of the survey studies as needed.

The graphical representation of the proposed model is shown in Figure 1

The total population size at time $i$ is denoted by $N_{i}$ with $N_{i}=P_{i}+E_{i}+A_{i}^{t}+A_{i}^{p}+V_{i}^{f}+V_{i}^{a}$. The dynamics of this model are governed by the following nonlinear system of difference equations:

$$
\begin{aligned}
P_{i+1}= & \Lambda+(1-\mu) P_{i}-\alpha \frac{P_{i} E_{i}}{N}-\beta(1-\sigma) \frac{P_{i} A_{i}^{p}}{N} \\
& -\beta \sigma \frac{P_{i} A_{i}^{t}}{N} \\
E_{i+1}= & (1-\mu) E_{i}-\delta \frac{E_{i} A_{i}^{t}}{N}+\alpha \frac{P_{i} E_{i}}{N}-\gamma \theta \frac{E_{i} V_{i}^{f}}{N} \\
& -\gamma(1-\theta) \frac{E_{i} V_{i}^{a}}{N} \\
A_{i+1}^{t}= & (1-\mu) A_{i}^{t}+\delta \frac{E_{i} A_{i}^{t}}{N}+\beta \sigma \frac{P_{i} A_{i}^{t}}{N}+(b-a) \frac{V_{i}^{f} A_{i}^{t}}{N} \\
& +(d-c) \frac{V_{i}^{a} A_{i}^{t}}{N} \\
A_{i+1}^{p}= & (1-\mu) A_{i}^{p}+\beta(1-\sigma) \frac{P_{i} A_{i}^{p}}{N} \\
V_{i+1}^{f}= & (1-\mu) V_{i}^{f}+\gamma \theta \frac{E_{i} V_{i}^{f}}{N}+(a-b) \frac{V_{i}^{f} A_{i}^{t}}{N} \\
& +(e-f) \frac{V_{i}^{f} V_{i}^{a}}{N}
\end{aligned}
$$

$$
\begin{aligned}
V_{i+1}^{a}= & (1-\mu) V_{i}^{a}+\gamma(1-\theta) \frac{E_{i} V_{i}^{a}}{N}+(c-d) \frac{V_{i}^{a} A_{i}^{t}}{N} \\
& +(f-e) \frac{V_{i}^{f} V_{i}^{a}}{N}
\end{aligned}
$$

where $P_{0} \geq 0, E_{0} \geq 0, A_{0}^{t} \geq 0, A_{0}^{p} \geq 0, V_{0}^{f} \geq 0$, and $V_{0}^{a} \geq 0$ are the given initial states.

\section{The Optimal Control Problem}

Our objective in this proposed strategy of control is to minimize the number of temporary abstainers $A_{i}^{t}$ and the voters against the political party $V_{i}^{a}$, maximize the number of the electors $E_{i}$ and the voters for the political party $V_{i}^{f}$ during the time step $i=0$ to $T$, and also minimize the cost spent in an awareness program and an election campaign.

In model (1) we include three controls $u_{i}=\left(u_{i, 0}, u_{i, 1}, \ldots\right.$, $\left.u_{i, T-1}\right)$ with $i=1,2,3$. The control $u_{1}$ represents the awareness campaign effort (time, money, and human resources) to motivate the potential electors to participate in the electoral process. The control $u_{2}$ represents the electoral campaign effort to impress the temporary abstainers to participate in the electoral process and support a political party by voting for it. Finally, $u_{3}$ measures the required persuasion effort to change the position of voters in favor of a political party. So the controlled mathematical system is given by the following system of difference equations.

$$
\begin{aligned}
P_{i+1}= & \Lambda+(1-\mu) P_{i}-\alpha \frac{P_{i} E_{i}}{N}-\beta(1-\sigma) \frac{P_{i} A_{i}^{p}}{N} \\
& -\beta \sigma \frac{P_{i} A_{i}^{t}}{N}-\epsilon_{1} u_{1, i} P_{i} \\
E_{i+1}= & (1-\mu) E_{i}-\delta \frac{E_{i} A_{i}^{t}}{N}+\alpha \frac{P_{i} E_{i}}{N}-\gamma \theta \frac{E_{i} V_{i}^{f}}{N}
\end{aligned}
$$




$$
\begin{aligned}
& -\gamma(1-\theta) \frac{E_{i} V_{i}^{a}}{N}+\epsilon_{1} u_{1, i} P_{i} \\
A_{i+1}^{t}= & (1-\mu) A_{i}^{t}+\delta \frac{E_{i} A_{i}^{t}}{N}+\beta \sigma \frac{P_{i} A_{i}^{t}}{N}+(b-a) \frac{V_{i}^{f} A_{i}^{t}}{N} \\
& +(d-c) \frac{V_{i}^{a} A_{i}^{t}}{N}-\epsilon_{2} u_{2, i} A_{i}^{t} \\
A_{i+1}^{p}= & (1-\mu) A_{i}^{p}+\beta(1-\sigma) \frac{P_{i} A_{i}^{p}}{N} \\
V_{i+1}^{f}= & (1-\mu) V_{i}^{f}+\gamma \theta \frac{E_{i} V_{i}^{f}}{N}+(a-b) \frac{V_{i}^{f} A_{i}^{t}}{N} \\
& +(e-f) \frac{V_{i}^{f} V_{i}^{a}}{N}+\epsilon_{3} u_{3, i} V_{i}^{a}+\epsilon_{2} u_{2, i} A_{i}^{t} \\
V_{i+1}^{a}= & (1-\mu) V_{i}^{a}+\gamma(1-\theta) \frac{E_{i} V_{i}^{a}}{N}+(c-d) \frac{V_{i}^{a} A_{i}^{t}}{N} \\
& +(f-e) \frac{V_{i}^{f} V_{i}^{a}}{N}-\epsilon_{3} u_{3, i} V_{i}^{a}
\end{aligned}
$$

where $P_{0} \geq 0, E_{0} \geq 0, A_{0}^{t} \geq 0, A_{0}^{p} \geq 0, V_{0}^{f} \geq 0$, and $V_{0}^{a} \geq 0$ are the given initial states and

$$
\epsilon_{i}=\left\{\begin{array}{l}
1 \\
0
\end{array} \text { for } i=1,2,3 .\right.
$$

From the system of difference equations (2), we can extract two models. The first controlled model achieves the objective of increasing the participation rate in the electoral process $\left(\epsilon_{1}=\epsilon_{2}=1\right)$ and the second controlled model leads to increase the number of voters for a political party $\left(\epsilon_{2}=\epsilon_{3}=1\right)$.

Then, the problem is to minimize the objective functional

$$
\begin{aligned}
& \left.J\left(u_{1}, u_{2}, u_{3}\right)\right)=H_{T} A_{T}^{t}+I_{T} V_{T}^{a}-K_{T} E_{T}-L_{T} V_{T}^{f} \\
& +\sum_{i=0}^{T-1}\left(H_{i} A_{i}^{t}+I_{i} V_{i}^{a}-K_{i} E_{i}-L_{i} V_{i}^{f}+\frac{M_{i}}{2} \epsilon_{1} u_{1, i}^{2}\right. \\
& \left.+\frac{N_{i}}{2} \epsilon_{2} u_{2, i}^{2}+\frac{O_{i}}{2} \epsilon_{3} u_{3, i}^{2}\right)
\end{aligned}
$$

where the parameters $H_{i}>0, I_{i}>0, K_{i}>0, L_{i}>0, M_{i}>$ $0, N_{i}>0$, and $O_{i}>0$ for $i \in\{0, \ldots, T\}$ are the cost coefficients. They are selected to weigh the relative importance of $A_{i}^{t}, V_{i}^{a}$, $E_{i}, V_{i}^{f}, u_{1, i}, u_{2, i}$, and $u_{3, i}$ at time $i$. $T$ is the final time.

In other words, we seek the optimal controls $u_{1}, u_{2}$, and $u_{3}$ such that

$$
J\left(u_{1}^{*}, u_{2}^{*}, u_{3}^{*}\right)=\min _{\left(u_{1}, u_{2}, u_{3}\right) \in U_{a d}^{3}} J\left(u_{1}, u_{2}, u_{3}\right)
$$

where $U_{a d}$ is the set of admissible controls defined by

$$
\begin{aligned}
U_{a d} & =\left\{u_{j}=\left(u_{j, 0}, u_{j, 1}, \ldots, u_{j, T-1}\right): e_{j} \leq u_{j, i} \leq f_{j}, \text { for } j\right. \\
& =1,2,3, i=0,1,2, \ldots, T-1\}
\end{aligned}
$$

The sufficient condition for the existence of an optimal control $\left(u_{1}^{*}, u_{2}^{*}, u_{3}^{*}\right)$ for problem (2) and (4) comes from the following theorem.

Theorem 1. There exist the optimal controls $u_{1}^{*}, u_{2}^{*}$, and $u_{3}^{*}$ such that

$$
J\left(u_{1}^{*}, u_{2}^{*}, u_{3}^{*}\right)=\min _{\left(u_{1}, u_{2}, u_{3}\right) \in U_{a d}^{3}} J\left(u_{1}, u_{2}, u_{3}\right)
$$

subject to the control system (2) with initial conditions.

Proof. Since the coefficients of the state equations are bounded and there are a finite number of time steps, $P=$ $\left(P_{0}, P_{1}, \ldots, P_{T}\right), E=\left(E_{0}, E_{1}, \ldots, E_{T}\right), A^{t}=\left(A_{0}^{t}, A_{1}^{t}, \ldots, A_{T}^{t}\right)$, $A^{p}=\left(A_{0}^{p}, A_{1}^{p}, \ldots, A_{T}^{p}\right), V^{f}=\left(V_{0}^{f}, V_{1}^{f}, \ldots, V_{T}^{f}\right)$, and $V^{a}=\left(V_{0}^{a}, V_{1}^{a}, \ldots, V_{T}^{a}\right)$ are uniformly bounded for all $\left(u_{1}, u_{2}, u_{3}\right)$ in the control set $U_{a d}^{3}$, and thus $J\left(u_{1}, u_{2}, u_{3}\right)$ is bounded for all $\left(u_{1}, u_{2}, u_{3}\right) \in U_{a d}^{3}$. Since $J\left(u_{1}, u_{2}, u_{3}\right)$ is bounded, $\inf _{\left(u_{1}, u_{2}, u_{3}\right) \in U_{a d}^{3}} J\left(u_{1}, u_{2}, u_{3}\right)$ is finite, and there exists a sequence $\left(u_{1}^{j}, u_{2}^{j}, u_{3}^{j}\right) \in U_{a d}^{3}$ such that $\lim _{j \rightarrow+\infty} J\left(u_{1}^{j}\right.$, $\left.u_{2}^{j}, u_{3}^{j}\right)=\inf _{\left(u_{1}, u_{2}, u_{3}\right) \in U_{a d}^{3}} J\left(u_{1}, u_{2}, u_{3}\right)$ and corresponding sequences of states $P^{j}, E^{j}, A^{t j}, A^{p j}, V^{f j}$, and $V^{a j}$. Since there is a finite number of uniformly bounded sequences, there exist $\left(u_{1}^{*}, u_{2}^{*}, u_{3}^{*}\right) \in U_{a d}^{3}$ and $P^{*}, E^{*}, A^{t *}, A^{p *}, V^{f *}$ and $V^{a *} \in \mathbb{R}^{T+1}$ such that on a subsequence, $\left(u_{1}^{j}, u_{2}^{j}, u_{3}^{j}\right) \longrightarrow\left(u_{1}^{*}, u_{2}^{*}, u_{3}^{*}\right)$, $P^{j} \longrightarrow P^{*}, E^{j} \longrightarrow E^{*}, A^{t j} \longrightarrow A^{t *}, A^{p j} \longrightarrow A^{p *}$, $V^{f j} \longrightarrow V^{f *}$, and $V^{a j} \longrightarrow V^{a *}$. Finally, due to the finite dimensional structure of system (2) and the objective function $J\left(u_{1}, u_{2}, u_{3}\right),\left(u_{1}^{*}, u_{2}^{*}, u_{3}^{*}\right)$ is an optimal control with corresponding states $P^{*}, E^{*}, A^{t *}, A^{p *}, V^{f *}$, and $V^{a *}$. Therefore $\inf _{\left(u_{1}, u_{2}, u_{3}\right) \in U_{a d}^{3}} J\left(u_{1}, u_{2}, u_{3}\right)$ is achieved.

We apply the discrete version of Pontryagin's Maximum Principle $[21,22,27,28]$. The key idea is introducing the adjoint function to attach the system of difference equations to the objective functional resulting in the formation of a function called the Hamiltonian. This principle converts the problem of finding the control to optimize the objective functional subject to the state difference equation with initial condition to find the control to optimize Hamiltonian pointwise (with respect to the control). by

Now we have the Hamiltonian $H_{i}$ at time step $i$, defined

$$
\begin{aligned}
H_{i}= & H_{i} A_{i}^{t}+I_{i} V_{i}^{a}-K_{i} E_{i}-L_{i} V_{i}^{f}+\frac{M_{i}}{2} \epsilon_{1} u_{1, i}^{2} \\
& +\frac{N_{i}}{2} \epsilon_{2} u_{2, i}^{2}+\frac{O_{i}}{2} \epsilon_{3} u_{3, i}^{2}+\sum_{j=1}^{6} \lambda_{j, i+1} f_{j, i+1}
\end{aligned}
$$

where $f_{j, i+1}$ is the right side of the system of difference equations (2) of the $j^{\text {th }}$ state variable at time step $i+1$.

Theorem 2. Given an optimal control $u_{i}^{*}=\left(u_{1, i}^{*}, u_{2, i}^{*}, u_{3, i}^{*}\right) \in$ $U_{a d}^{3}$ and solutions $P_{i}^{*}, E_{i}^{*}, A_{i}^{t *}, A_{i}^{p *}, V_{i}^{f *}$, and $V_{i}^{a *}$ of corresponding state system (2), there exist adjoint functions, $\lambda_{1, i}$, $\lambda_{2, i}, \lambda_{3, i}, \lambda_{4, i}, \lambda_{5, i}$, and $\lambda_{6, i}$, satisfying 


$$
\begin{aligned}
& \lambda_{1, i}=\lambda_{1, i+1}\left\{(1-\mu)-\alpha \frac{E_{i}}{N}-\beta(1-\sigma) \frac{A_{i}^{p}}{N}-\beta \sigma \frac{A_{i}^{t}}{N}\right. \\
& \left.-\epsilon_{1} u_{1, i}\right\}+\lambda_{2, i+1}\left\{\alpha \frac{E_{i}}{N}+\epsilon_{1} u_{1, i}\right\}+\lambda_{3, i+1}\left\{\beta \sigma \frac{A_{i}^{t}}{N}\right\} \\
& +\lambda_{4, i+1}\left\{\beta(1-\sigma) \frac{A_{i}^{p}}{N}\right\} \\
& \lambda_{2, i}=-K_{i}+\lambda_{1, i+1}\left\{-\alpha \frac{P_{i}}{N}\right\}+\lambda_{2, i+1}\left\{(1-\mu)-\delta \frac{A_{i}^{t}}{N}\right. \\
& \left.+\alpha \frac{P_{i}}{N}-\gamma \theta \frac{V_{i}^{f}}{N}-\gamma(1-\theta) \frac{V_{i}^{a}}{N}\right\}+\lambda_{3, i+1}\left\{\delta \frac{A_{i}^{t}}{N}\right\} \\
& +\lambda_{5, i+1}\left\{\gamma \theta \frac{V_{i}^{f}}{N}\right\}+\lambda_{6, i+1}\left\{\gamma(1-\theta) \frac{V_{i}^{a}}{N}\right\} \\
& \lambda_{3, i}=H_{i}+\lambda_{1, i+1}\left\{-\beta \sigma \frac{P_{i}}{N}\right\}+\lambda_{2, i+1}\left\{-\delta \frac{E_{i}}{N}\right\} \\
& +\lambda_{5, i+1}\left\{(a-b) \frac{V_{i}^{f}}{N}+\epsilon_{2} u_{2, i}\right\} \\
& +\lambda_{6, i+1}\left\{(c-d) \frac{V_{i}^{a}}{N}\right\}+\lambda_{3, i+1}\left\{(1-\mu)+\delta \frac{E_{i}}{N}\right. \\
& \left.+\beta \sigma \frac{P_{i}}{N}+(b-a) \frac{V_{i}^{f}}{N}+(d-c) \frac{V_{i}^{a}}{N}-\epsilon_{2} u_{2, i}\right\} \\
& \lambda_{4, i}=\lambda_{1, i+1}\left\{-\beta(1-\sigma) \frac{P_{i}}{N}\right\}+\lambda_{4, i+1}\{(1-\mu) \\
& \left.+\beta(1-\sigma) \frac{P_{i}}{N}\right\} \\
& \lambda_{5, i}=-L_{i}+\lambda_{2, i+1}\left\{-\gamma \theta \frac{E_{i}}{N}\right\}+\lambda_{3, i+1}\left\{(b-a) \frac{A_{i}^{t}}{N}\right\} \\
& +\lambda_{5, i+1}\left\{(1-\mu)+\gamma \theta \frac{E_{i}}{N}+(a-b) \frac{A_{i}^{t}}{N}\right. \\
& \left.+(e-f) \frac{V_{i}^{a}}{N}\right\}+\lambda_{6, i+1}\left\{(f-e) \frac{V_{i}^{a}}{N}\right\} \\
& \lambda_{6, i}=I_{i}+\lambda_{2, i+1}\left\{-\gamma(1-\theta) \frac{E_{i}}{N}\right\} \\
& +\lambda_{3, i+1}\left\{(d-c) \frac{A_{i}^{t}}{N}\right\}+\lambda_{5, i+1}\left\{(e-f) \frac{V_{i}^{f}}{N}\right. \\
& \left.+\epsilon_{3} u_{3, i}\right\}+\lambda_{6, i+1}\left\{(1-\mu)+\gamma(1-\theta) \frac{E_{i}}{N}\right. \\
& \left.+(c-d) \frac{A_{i}^{t}}{N}+(f-e) \frac{V_{i}^{f}}{N}-\epsilon_{3} u_{3, i}\right\}
\end{aligned}
$$

with the transversality conditions at time $T$

$$
\begin{aligned}
& \lambda_{1, T}=\lambda_{4, T}=0, \\
& \lambda_{2, T}=-K_{i}, \\
& \lambda_{3, T}=H_{i}, \\
& \lambda_{5, T}=-L_{i}, \\
& \lambda_{6, T}=I_{i}
\end{aligned}
$$

Furthermore, for $i=0,1, \ldots, T-1$ and for $\epsilon_{1}=\epsilon_{2}=\epsilon_{3}=$ 1 , the optimal controls $u_{1, i}^{*}, u_{2, i}^{*}$, and $u_{3, i}^{*}$ are given by

$$
\begin{aligned}
& u_{1, i}^{*}=\min \left(f_{1}, \max \left(e_{1}, \frac{1}{M_{i}} P_{i}\left(\lambda_{1, i+1}-\lambda_{2, i+1}\right)\right)\right) . \\
& u_{2, i}^{*}=\min \left(f_{2}, \max \left(e_{2}, \frac{1}{N_{i}} A_{i}^{t}\left(\lambda_{3, i+1}-\lambda_{5, i+1}\right)\right)\right) . \\
& u_{3, i}^{*}=\min \left(f_{3}, \max \left(e_{3}, \frac{1}{O_{i}} V_{i}^{a}\left(\lambda_{6, i+1}-\lambda_{5, i+1}\right)\right)\right) .
\end{aligned}
$$

Proof. The Hamiltonian at time step $i$ is given by

$$
\begin{aligned}
H_{i} & =H_{i} A_{i}^{t}+I_{i} V_{i}^{a}-K_{i} E_{i}-L_{i} V_{i}^{f}+\frac{M_{i}}{2} \epsilon_{1} u_{1, i}^{2}+\frac{N_{i}}{2} \\
& \cdot \epsilon_{2} u_{2, i}^{2}+\frac{O_{i}}{2} \epsilon_{3} u_{3, i}^{2}+\lambda_{1, i+1}\left\{\Lambda+(1-\mu) P_{i}-\alpha \frac{P_{i} E_{i}}{N}\right. \\
& \left.-\beta(1-\sigma) \frac{P_{i} A_{i}^{p}}{N}-\beta \sigma \frac{P_{i} A_{i}^{t}}{N}-\epsilon_{1} u_{1, i} P_{i}\right\} \\
& +\lambda_{2, i+1}\left\{(1-\mu) E_{i}-\delta \frac{E_{i} A_{i}^{t}}{N}+\alpha \frac{P_{i} E_{i}}{N}-\gamma \theta \frac{E_{i} V_{i}^{f}}{N}\right. \\
& \left.+\gamma(1-\theta) \frac{E_{i} V_{i}^{a}}{N}+\epsilon_{1} u_{1, i} P_{i}\right\}+\lambda_{3, i+1}\left\{(1-\mu) A_{i}^{t}\right. \\
& +\delta \frac{E_{i} A_{i}^{t}}{N}+\beta \sigma \frac{P_{i} A_{i}^{t}}{N}+(b-a) \frac{V_{i}^{f} A_{i}^{t}}{N} \\
& +\gamma \theta \frac{E_{i} V_{i}^{f}}{N}+(a-b) \frac{V_{i}^{f} A_{i}^{t}}{N}+(e-f) \frac{V_{i}^{f} V_{i}^{a}}{N} \\
& \left.+\beta(1-\sigma) \frac{P_{i} A_{i}^{p}}{N}\right\}+\lambda_{5, i+1}^{t}\left\{(1-\mu) V_{i}^{f}\right. \\
& \left.\left.+\epsilon_{2}^{a}+\epsilon_{2} u_{2, i} A_{i}^{t}\right\}+\lambda_{6, i+1} A_{i}^{t}\right\}+\lambda_{4, i+1}\left\{(1-\mu) A_{i}^{p}\right.
\end{aligned}
$$




$$
\begin{aligned}
& +\gamma(1-\theta) \frac{E_{i} V_{i}^{a}}{N}+(c-d) \frac{V_{i}^{a} A_{i}^{t}}{N}+(f-e) \frac{V_{i}^{f} V_{i}^{a}}{N} \\
& \left.-\epsilon_{3} u_{3, i} V_{i}^{a}\right\}
\end{aligned}
$$

For $i=0,1, \ldots, T-1$, the adjoint equations and transversality conditions can be obtained by using Pontryagin's Maximum Principle, in discrete time, given in $[11,21,22,27,28]$ such that

$$
\begin{aligned}
& \lambda_{1, i}=\frac{\partial H_{i}}{\partial P_{i}}, \\
& \lambda_{1, T}=0 \\
& \lambda_{2, i}=\frac{\partial H_{i}}{\partial E_{i}}, \\
& \lambda_{2, T}=-K_{T} \\
& \lambda_{3, i}=\frac{\partial H_{i}}{\partial A_{i}^{t}}, \\
& \lambda_{3, T}=H_{T} \\
& \lambda_{4, i}=\frac{\partial H_{i}}{\partial A_{i}^{p}}, \\
& \lambda_{4, T}=0 \\
& \lambda_{5, i}=\frac{\partial H_{i}}{\partial V_{i}^{f}}, \\
& \lambda_{5, T}=-L_{T} \\
& \lambda_{6, i}=\frac{\partial H_{i}}{\partial V_{i}^{a}}, \\
& \lambda_{6, T}=I_{T}
\end{aligned}
$$

For $i=0,1, \ldots, T-1$, the optimal controls $u_{1, i}^{*}, u_{2, i}^{*}$, and $u_{3, i}^{*}$ can be solved from the optimality condition,

$$
\begin{gathered}
\frac{\partial H_{i}}{\partial u_{1, i}}=0, \\
\frac{\partial H_{i}}{\partial u_{2, i}}=0 \\
\frac{\partial H_{i}}{\partial u_{3, i}}=0 ;
\end{gathered}
$$

that is,

$$
\begin{aligned}
& \frac{\partial H_{i}}{\partial u_{1, i}}=M_{i} \epsilon_{1} u_{1, i}+\lambda_{1, i+1}\left\{-\epsilon_{1} P_{i}\right\}+\lambda_{2, i+1}\left\{\epsilon_{1} P_{i}\right\}=0 . \\
& \frac{\partial H_{i}}{\partial u_{2, i}}=N_{i} \epsilon_{2} u_{2, i}+\lambda_{3, i+1}\left\{-\epsilon_{2} A_{i}^{t}\right\}+\lambda_{5, i+1}\left\{\epsilon_{2} A_{i}^{t}\right\}=0 .
\end{aligned}
$$

$$
\frac{\partial H_{i}}{\partial u_{3, i}}=O_{i} \epsilon_{3} u_{3, i}+\lambda_{5, i+1}\left\{\epsilon_{3} V_{i}^{a}\right\}+\lambda_{6, i+1}\left\{-\epsilon_{3} V_{i}^{a}\right\}=0
$$

So, for $\epsilon_{1}=\epsilon_{2}=\epsilon_{3}=1$, we have

$$
\begin{aligned}
& u_{1, i}=\frac{1}{M_{i}} P_{i}\left(\lambda_{1, i+1}-\lambda_{2, i+1}\right) . \\
& u_{2, i}=\frac{1}{N_{i}} A_{i}^{t}\left(\lambda_{3, i+1}-\lambda_{5, i+1}\right) . \\
& u_{3, i}=\frac{1}{O_{i}} V_{i}^{a}\left(\lambda_{6, i+1}-\lambda_{5, i+1}\right) .
\end{aligned}
$$

However, if $\epsilon_{i}=0$ for $i=1,2,3$, the control attached to this case will be eliminated and removed.

By the bounds in $U_{a d}$ of the controls, it is easy to obtain $u_{1, i}^{*}, u_{2, i}^{*}$, and $u_{3, i}^{*}$ in the form of (11)-(12)-(13).

\section{Numerical Simulation}

4.1. Algorithm. In this section, we present the results obtained by solving numerically the optimality system. This system consists of the state system, adjoint system, initial and final time conditions, and the controls characterization. So the optimality system is given by the following.

Step 1. $P_{0}=p_{0}, E_{0}=e_{0}, A_{0}^{t}=a_{0}^{t}, A_{0}^{p}=a_{0}^{p}, V_{0}^{f}=v_{0}^{f}, V_{0}^{a}=v_{0}^{a}$, $\lambda_{1, T}=\lambda_{4, T}=0, \lambda_{2, T}=-K_{i}, \lambda_{3, T}=H_{i}, \lambda_{5, T}=-L_{i}, \lambda_{6, T}=I_{i}$, and given $u_{1,0}^{*}, u_{2,0}^{*}$, and $u_{3,0}^{*}$.

Step 2. For $i=0,1, \ldots, T-1$, do the following:

$$
\begin{aligned}
& P_{i+1}=\Lambda+(1-\mu) P_{i}-\alpha \frac{P_{i} E_{i}}{N}-\beta(1-\sigma) \frac{P_{i} A_{i}^{p}}{N}-\beta \sigma \\
& \quad \cdot \frac{P_{i} A_{i}^{t}}{N}-\epsilon_{1} u_{1, i} P_{i} \\
& E_{i+1}=(1-\mu) E_{i}-\delta \frac{E_{i} A_{i}^{t}}{N}+\alpha \frac{P_{i} E_{i}}{N}-\gamma \theta \frac{E_{i} V_{i}^{f}}{N}-\gamma(1 \\
& -\theta) \frac{E_{i} V_{i}^{a}}{N}+\epsilon_{1} u_{1, i} P_{i} \\
& A_{i+1}^{t}=(1-\mu) A_{i}^{t}+\delta \frac{E_{i} A_{i}^{t}}{N}+\beta \sigma \frac{P_{i} A_{i}^{t}}{N}+(b-a) \frac{V_{i}^{f} A_{i}^{t}}{N} \\
& \quad+(d-c) \frac{V_{i}^{a} A_{i}^{t}}{N}-\epsilon_{2} u_{2, i} A_{i}^{t} \\
& A_{i+1}^{p}=(1-\mu) A_{i}^{p}+\beta(1-\sigma) \frac{P_{i} A_{i}^{p}}{N} \\
& V_{i+1}^{f}=(1-\mu) V_{i}^{f}+\gamma \theta \frac{E_{i} V_{i}^{f}}{N}+(a-b) \frac{V_{i}^{f} A_{i}^{t}}{N}+(e \\
& N
\end{aligned}
$$




$$
\begin{aligned}
& V_{i+1}^{a}=(1-\mu) V_{i}^{a}+\gamma(1-\theta) \frac{E_{i} V_{i}^{a}}{N}+(c-d) \frac{V_{i}^{a} A_{i}^{t}}{N} \\
& +(f-e) \frac{V_{i}^{f} V_{i}^{a}}{N}-\epsilon_{3} u_{3, i} V_{i}^{a} \\
& \lambda_{1, T-i}=\lambda_{1, T-i+1}\left\{(1-\mu)-\alpha \frac{E_{i}}{N}-\beta(1-\sigma) \frac{A_{i}^{p}}{N}\right. \\
& \left.-\beta \sigma \frac{A_{i}^{t}}{N}-\epsilon_{1} u_{1, i}\right\}+\lambda_{2, T-i+1}\left\{\alpha \frac{E_{i}}{N}+\epsilon_{1} u_{1, i}\right\} \\
& +\lambda_{3, T-i+1}\left\{\beta \sigma \frac{A_{i}^{t}}{N}\right\}+\lambda_{4, T-i+1}\left\{\beta(1-\sigma) \frac{A_{i}^{p}}{N}\right\} \\
& \lambda_{2, T-i}=-K_{i}+\lambda_{1, T-i+1}\left\{-\alpha \frac{P_{i}}{N}\right\}+\lambda_{2, T-i+1}\{(1-\mu) \\
& \left.-\delta \frac{A_{i}^{t}}{N}+\alpha \frac{P_{i}}{N}-\gamma \theta \frac{V_{i}^{f}}{N}-\gamma(1-\theta) \frac{V_{i}^{a}}{N}\right\} \\
& +\lambda_{3, T-i+1}\left\{\delta \frac{A_{i}^{t}}{N}\right\}+\lambda_{5, T-i+1}\left\{\gamma \theta \frac{V_{i}^{f}}{N}\right\} \\
& +\lambda_{6, T-i+1}\left\{\gamma(1-\theta) \frac{V_{i}^{a}}{N}\right\} \\
& \lambda_{3, T-i}=H_{i}+\lambda_{1, T-i+1}\left\{-\beta \sigma \frac{P_{i}}{N}\right\}+\lambda_{2, T-i+1}\left\{-\delta \frac{E_{i}}{N}\right\} \\
& +\lambda_{5, T-i+1}\left\{(a-b) \frac{V_{i}^{f}}{N}+\epsilon_{2} u_{2, i}\right\} \\
& +\lambda_{6, T-i+1}\left\{(c-d) \frac{V_{i}^{a}}{N}\right\}+\lambda_{3, T-i+1}\left\{(1-\mu)+\delta \frac{E_{i}}{N}\right. \\
& \left.+\beta \sigma \frac{P_{i}}{N}+(b-a) \frac{V_{i}^{f}}{N}+(d-c) \frac{V_{i}^{a}}{N}-\epsilon_{2} u_{2, i}\right\} \\
& \lambda_{4, T-i}=\lambda_{1, T-i+1}\left\{-\beta(1-\sigma) \frac{P_{i}}{N}\right\}+\lambda_{4, T-i+1}\{(1-\mu) \\
& \left.+\beta(1-\sigma) \frac{P_{i}}{N}\right\} \\
& \lambda_{5, T-i}=-L_{i}+\lambda_{2, T-i+1}\left\{-\gamma \theta \frac{E_{i}}{N}\right\} \\
& +\lambda_{3, T-i+1}\left\{(b-a) \frac{A_{i}^{t}}{N}\right\}+\lambda_{5, T-i+1}\{(1-\mu) \\
& \left.+\gamma \theta \frac{E_{i}}{N}+(a-b) \frac{A_{i}^{t}}{N}+(e-f) \frac{V_{i}^{a}}{N}\right\} \\
& +\lambda_{6, T-i+1}\left\{(f-e) \frac{V_{i}^{a}}{N}\right\}
\end{aligned}
$$$$
\lambda_{6, T-i}=I_{i}+\lambda_{2, T-i+1}\left\{-\gamma(1-\theta) \frac{E_{i}}{N}\right\}
$$

end for.

Step 3. For $i=0,1, \ldots, T$, write

$$
\begin{gathered}
P_{i}^{*}=P_{i}, \\
E_{i}^{*}=E_{i}, \\
A_{i}^{t *}=A_{i}^{t}, \\
A_{i}^{p^{*}}=A_{i}^{p}, \\
V_{i}^{f *}=V_{i}^{f}, \\
V_{i}^{a *}=V_{i}^{a}, \\
u_{1, i}^{*}=u_{1, i}, \\
u_{2, i}^{*}=u_{2, i}, \\
u_{3, i}^{*}=u_{3, i}
\end{gathered}
$$

end for.

In this formulation, there were initial conditions for the state variables and terminal conditions for the adjoints. That is, the optimality system is a two-point boundary value problem with separated boundary conditions at times step $i=0$ and $i=T$. We solve the optimality system by an iterative method with forward solving of the state system followed by backward solving of the adjoint system. We start with an initial guess for the controls at the first iteration and then before the next iteration we update the controls by using the 


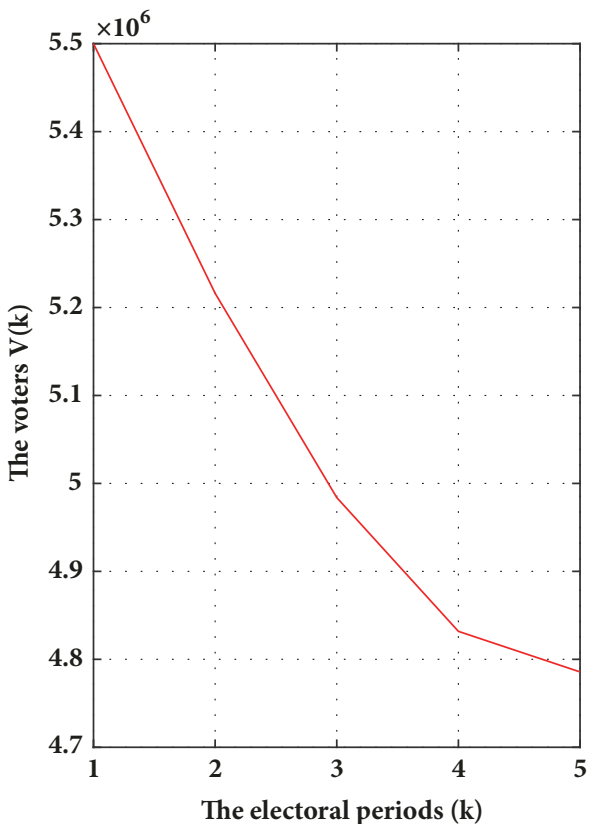

(a)

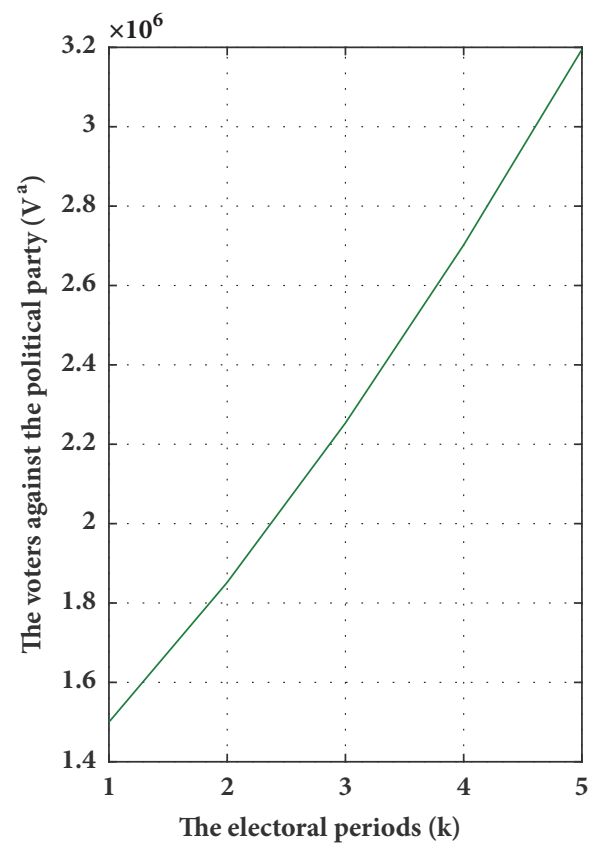

(c)

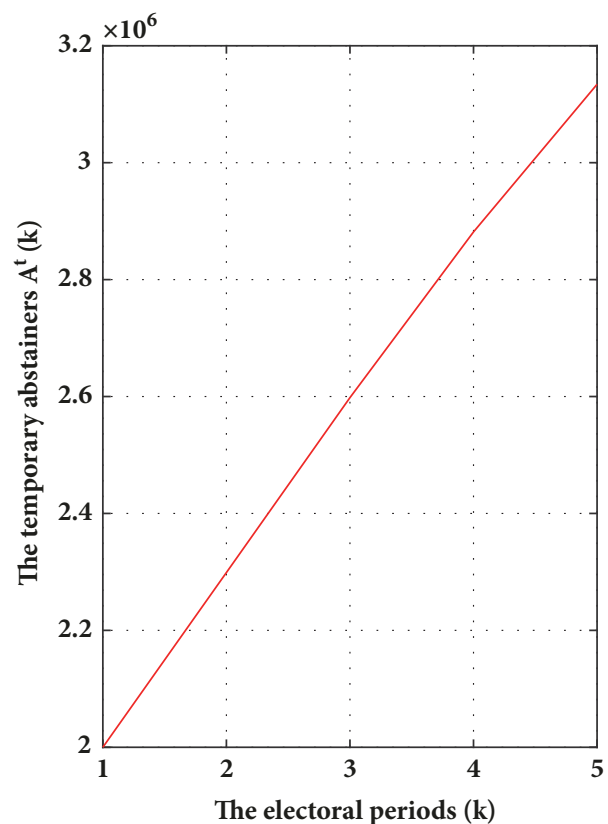

(b)

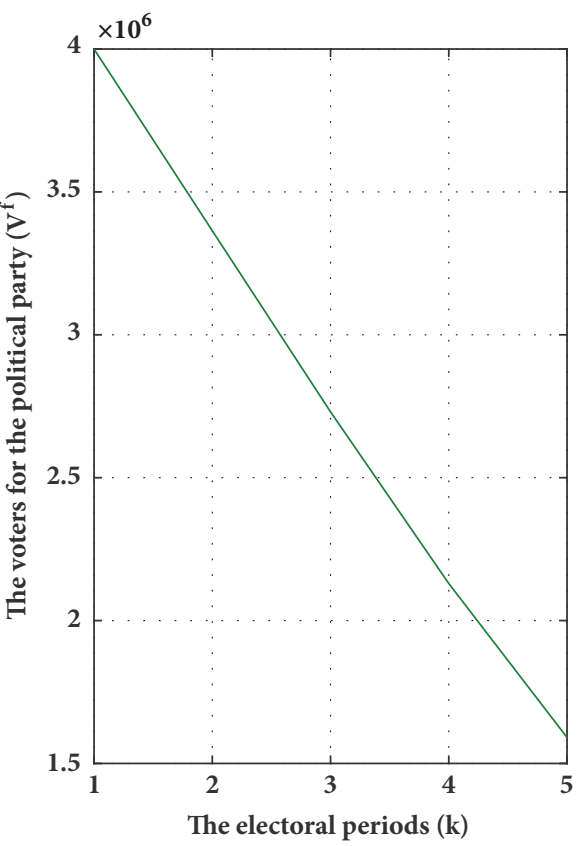

(d)

Figure 2

characterization. We continue until convergence of successive iterates is achieved.

4.2. Discussion. We begin by presenting, in Figure 2, the simulations concerning the evolution of model (1) without control functions.

Using the parameters of Table 1, we observe that the number of voters participating in the electoral process decreases significantly (Figure 2(a)). In addition, the number of electors who abstain voting increases (Figure 2(b)). On the other hand, the number of the voters against the political party increases clearly (Figure 2(c)); contrariwise, the number of voters supporting the political party decreases (Figure 2(d)).

This requires the political party concerned with these statistical data to seek an effective awareness and electoral campaign strategy to reverse the results.

The proposed control strategy in this work helps to achieve several objectives.

Objective 1. Increasing the participation rate in elections knowing that the participation rate has an important political interpretation. 


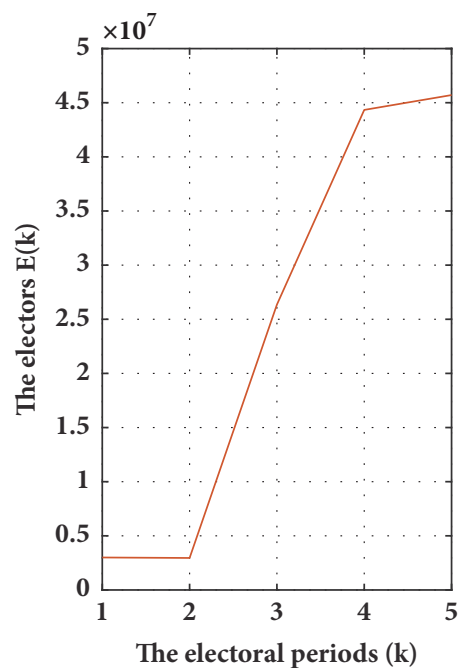

The evolution of $\mathrm{E}$ with controls $\mathrm{u} 1$ and $\mathrm{u} 2$

(a)

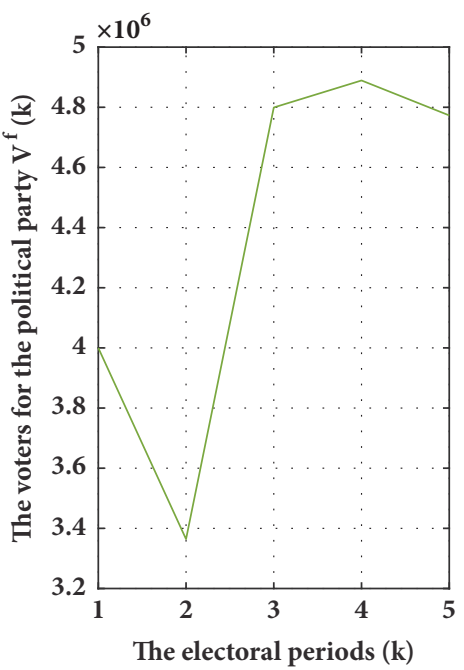

The evolution of $v^{f}$ with controls $\mathrm{u} 1$ and $\mathrm{u} 2$

(c)

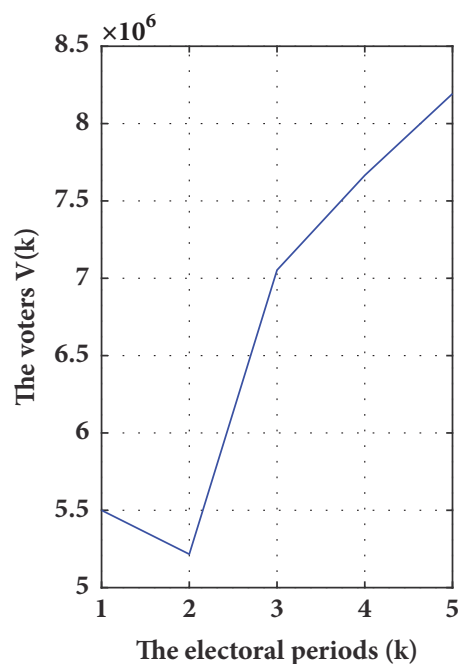

$V$ : The number of voters with controls $\mathrm{u} 1$ and $\mathrm{u} 2$

(b)

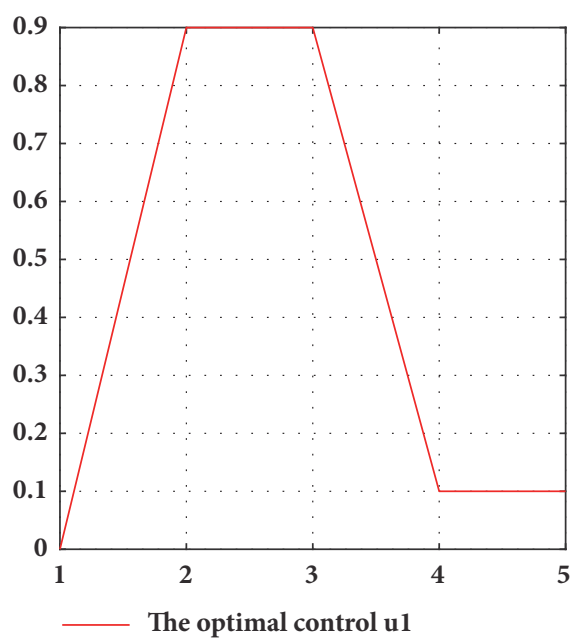

(d)

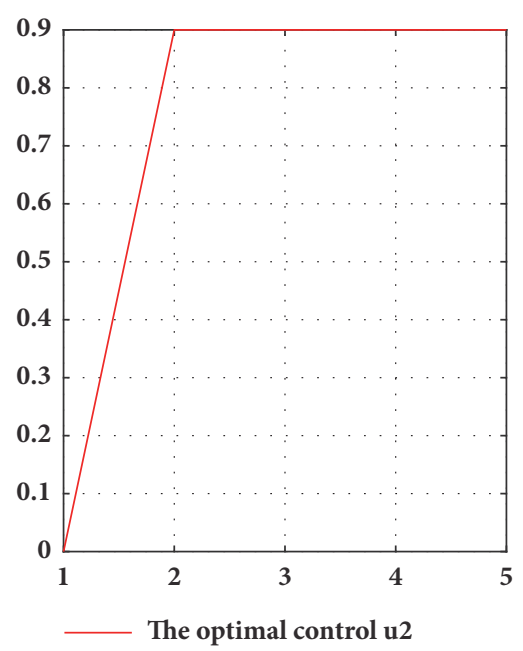

(e)

Figure 3 


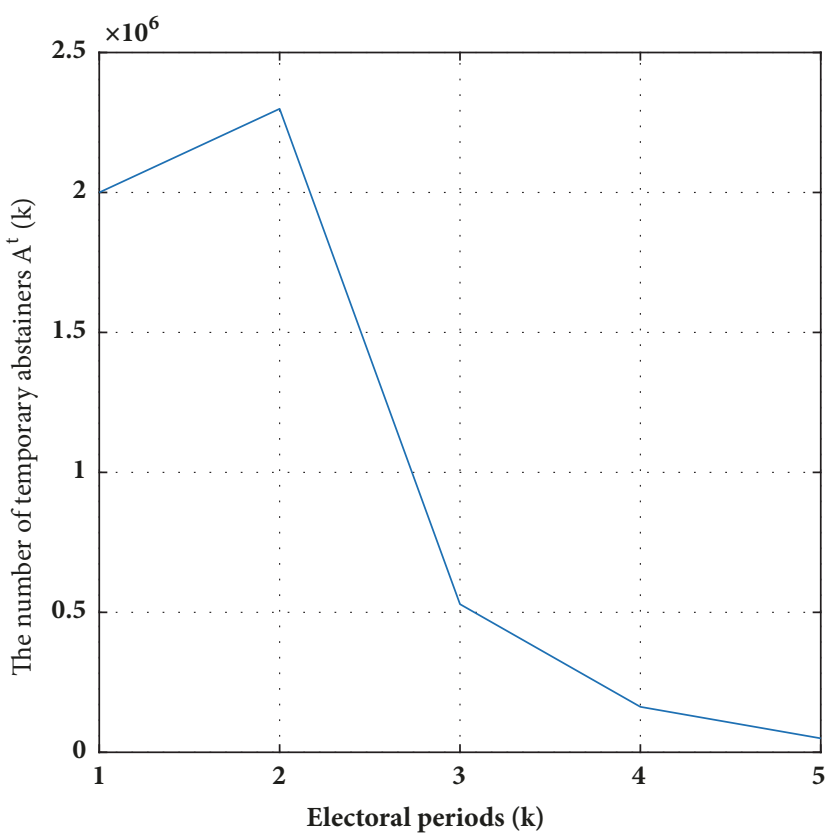

$\mathrm{A}^{\mathrm{t}}$ :The number of the temporary abstainers with control u2

(a)

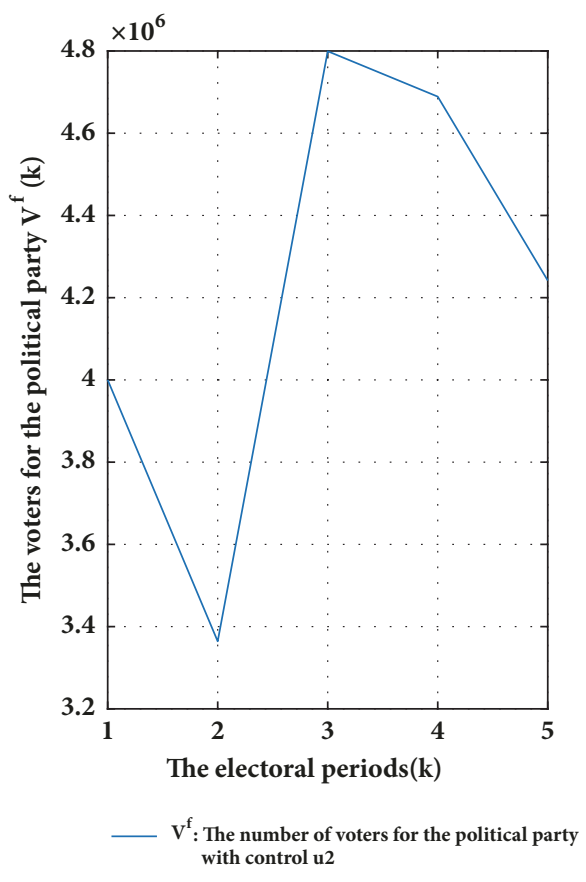

(b)

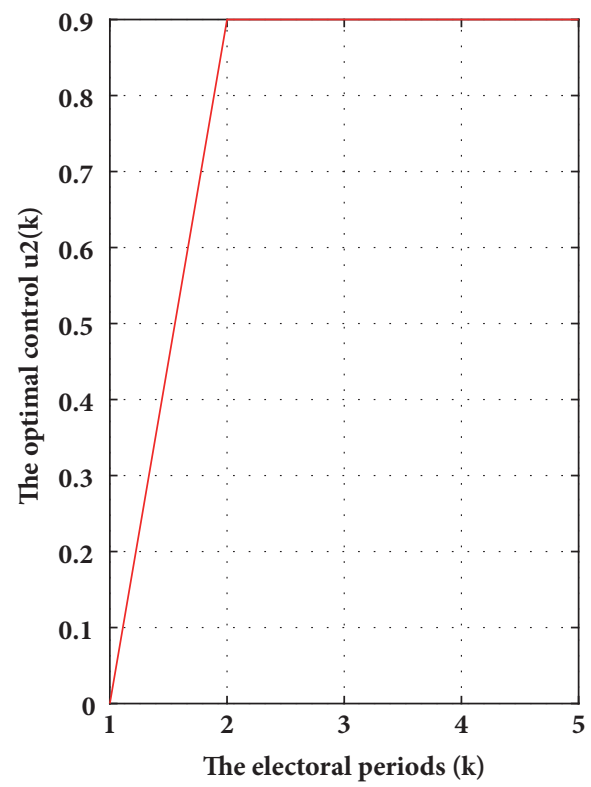

(c)

FIGURE 4

TABLE 1: The description of parameters used for the definition of discrete time systems (1).

\begin{tabular}{|c|c|c|c|c|c|c|c|}
\hline$P_{0}$ & $E_{0}$ & $A_{0}^{t}$ & $A_{0}^{p}$ & $V_{0}^{f}$ & $V_{0}^{a}$ & $N$ & $\Lambda$ \\
\hline $8.10^{6}$ & $3.10^{6}$ & $2.10^{6}$ & $5.10^{5}$ & $4.10^{6}$ & $1,5.10^{6}$ & $23,5.10^{6}$ & $8.10^{6}$ \\
\hline$\mu$ & $\alpha$ & $\beta$ & $\sigma$ & $\delta$ & $\alpha$ & $\gamma$ & \\
\hline 0,0048 & 0,001 & 0,2346 & 0,1000 & 0,0254 & 0,0010 & 0,0422 & \\
\hline$\theta$ & $a$ & $b$ & $c$ & $d$ & $e$ & $f$ & \\
\hline 0,8000 & 0,0020 & 0,9000 & 0.6264 & 0.0095 & 0.0037 & 0.8265 & \\
\hline
\end{tabular}




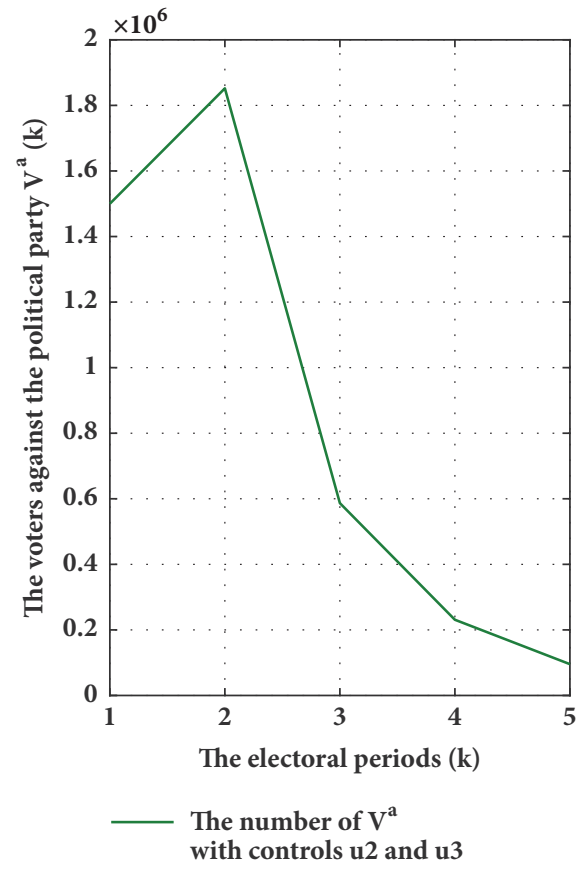

(a)

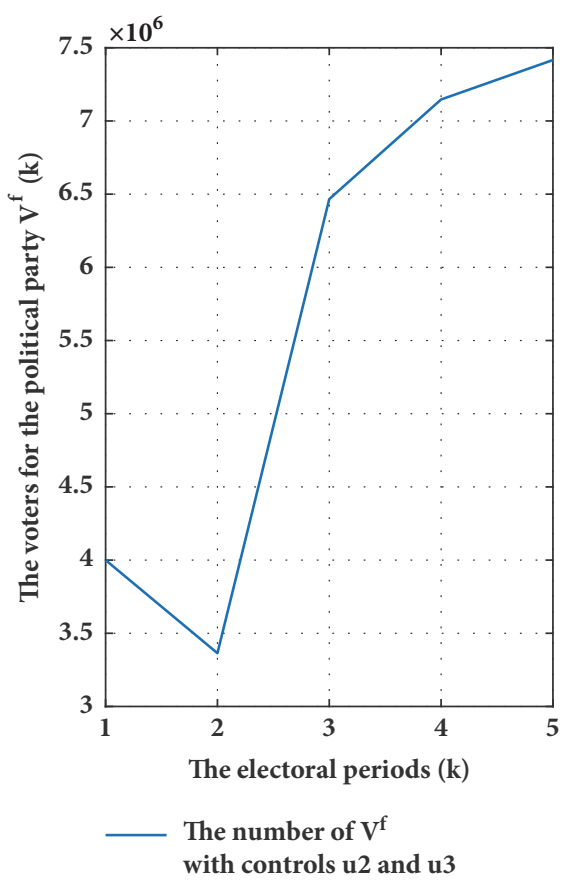

(b)
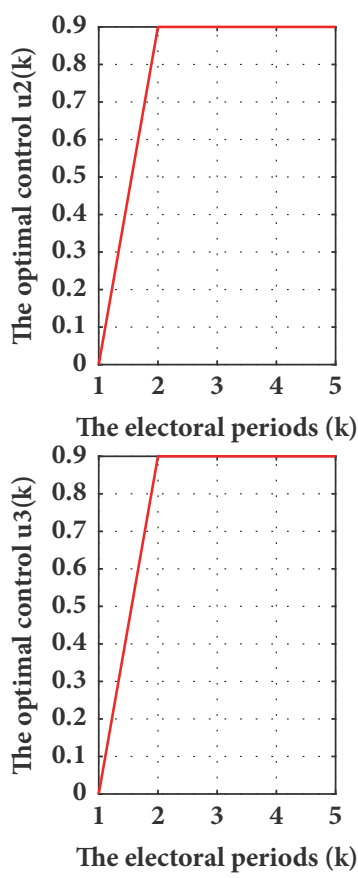

(c)

FiguRE 5

In democratic countries, the participation rate has an important political interpretation because it gives political parties that win elections a very strong political legitimacy, that is, the reason why every political party wishes to have a victory in elections with a very high participation rate. This requires contributing with other political competitors to motivate citizens to participate in the vote regardless of the parties they vote for them.

To achieve this objective, we activate two controls in our proposed control strategy (case of $\epsilon_{1}=\epsilon_{2}=1$ ).

From Figures 3(a)-3(e), we observe that the number of the electors $E_{k}$ and the number of the voters $V_{k}=V_{k}^{f}+$ $V_{k}^{a}$ increase clearly. Also, we observe that when we have an increase in the participation rate, the number of the voters for the political party $V_{k}^{f}$ increases. The figures (Figure 3(d)) and (Figure 3(e)) give the optimal controls $u_{1}$ and $u_{2}$.

Objective 2. Decreasing the number of people who abstain temporarily in participating in the election and who negatively affect the individuals participating in the elections (case of $\left.\epsilon_{2}=1\right)$.

From Figures 4(a)-4(c) we easily observe that the number of temporary abstainers decreases (Figure 4(a)). The decrease of the number of $A^{t}$ has positively influenced the growth of the individuals who vote for the political party (Figure 4(b)). However, this growth is not continuous throughout the study period which necessitates combining this proposed control strategy with another aimed at keeping the number of $V^{f}$ increases continuously during the study period. The figure (Figure 4(c)) gives the optimal control $u_{2}$.
Objective 3. Increasing the number of individuals who vote for the political party (Figure 5(b)) and at the same time decreasing the number of voters against the political party (Figure 5(a)) (case of $\epsilon_{2}=\epsilon_{3}=1$ ).

Objective 4. Wining the elections with a high participation rate. To achieve this objective we activate the three optimal controls (case of $\epsilon_{1}=\epsilon_{2}=\epsilon_{3}=1$ ).

From Figures 6(a)-6(e) we observe easily that the number of voters increases (Figure 6(a)) and the number of temporary abstainers decreases (Figure 6(b)) which leads to a high participation rate in the election process. Also, using this strategy, the political party managed to increase the number of voters for it (Figure 6(d)) and decreased significantly the number of voters against it (Figure 6(c)). The graphs in (Figure 6(e)) give the optimal controls $u_{1}, u_{2}$, and $u_{3}$.

Finally, these results prove the effectiveness of the proposed control strategies and the validity of the mathematical model.

\section{Conclusion}

In this work, we formulate a discrete mathematical model that describes the dynamics of citizens who have the right to vote and their electoral behavior with regard to a political party during an awareness program or an electoral campaign. Also, we propose an optimal strategy for an awareness program or an election campaign that helps politicians to distinguish between different categories of voters in order to increase the participation rate in the electoral process and obtain the greatest possible number of votes with a minimal effort. In this strategy, we introduced three controls. The first control 


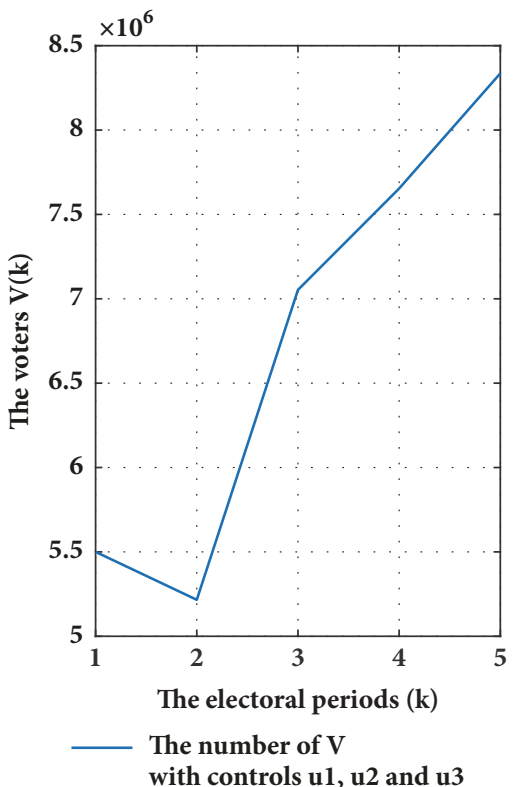

(a)

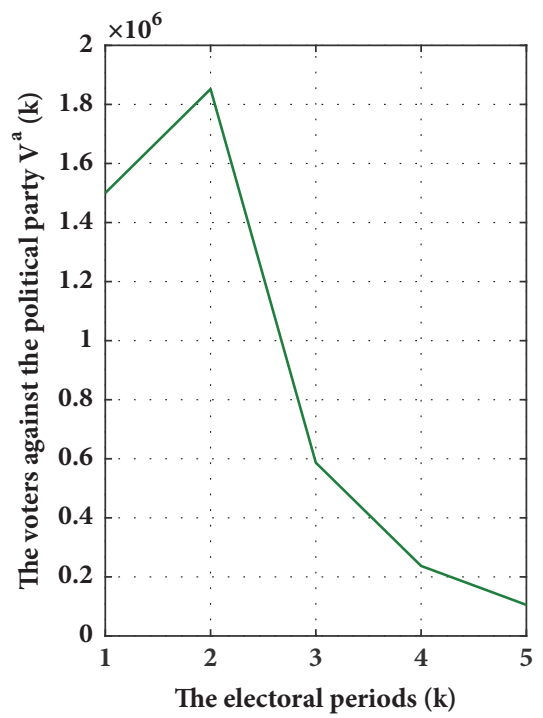

The number of $\mathrm{V}^{\mathrm{a}}$ with controls $\mathrm{u} 1, \mathrm{u} 2$ and $\mathrm{u} 3$

(c)

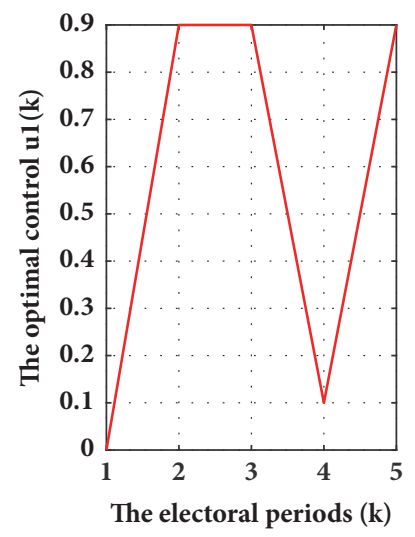

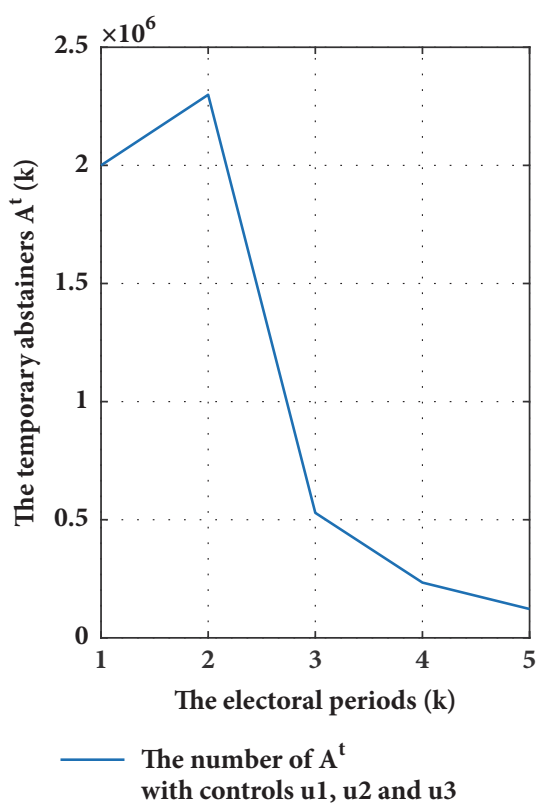

(b)

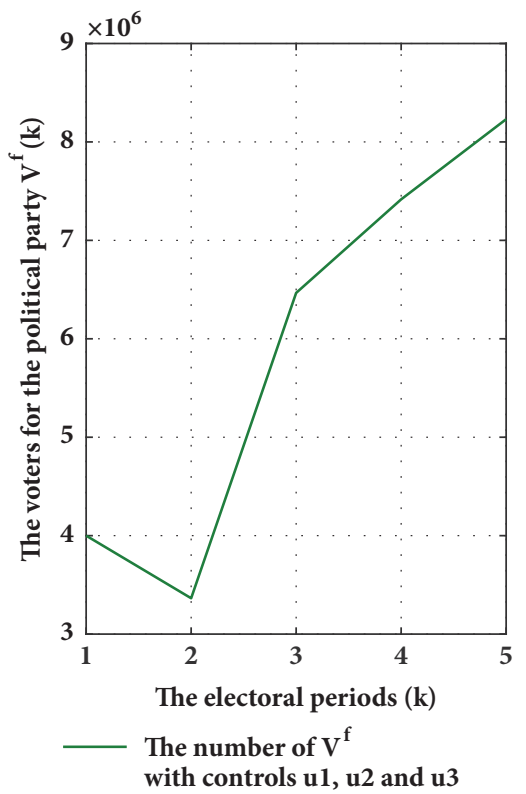

(d)

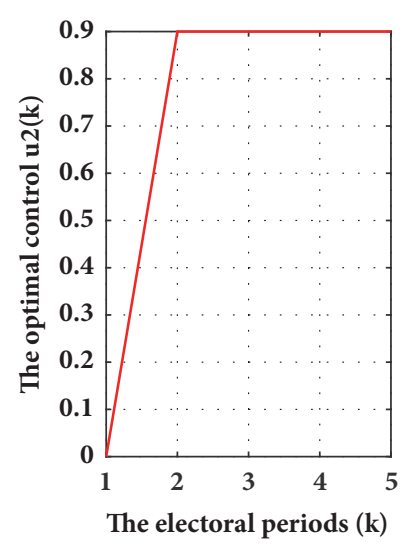

(e)

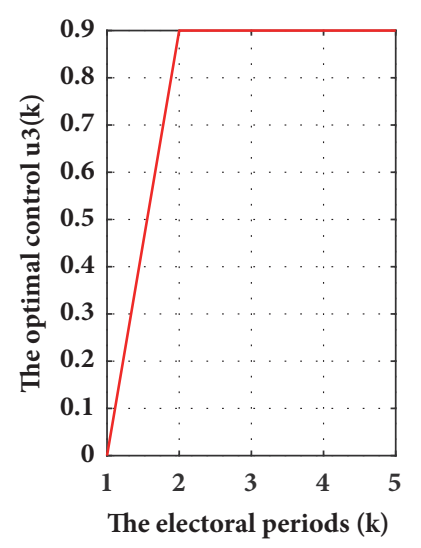

FIgURE 6 
represented the awareness campaign effort (time, money, and human resources) to motivate the potential electors to participate in the electoral process. The second control characterized the electoral campaign effort to impress the temporary abstainers to participate in the electoral process and support a political party by voting for it. Finally, the third control measured the required persuasion effort to change the position of voters in favor of a political party. Pontryagin's Maximum Principle, in discrete time, is used to characterize the optimal controls and the optimality system is solved by an iterative method.

Consequently, the proposed modeling and optimal control strategies have led to achieve several objectives:

(i) Increasing the participation rate in elections knowing that the participation rate has an important political interpretation.

(ii) Decreasing the number of people who abstain temporarily in participating in the election and who negatively affect the individuals participating in the elections.

(iii) Increasing the number of individuals who vote for the political party and at the same time decreasing the number of voters against the political party.

(iv) Wining the elections with a high participation rate.

The numerical simulation is carried out using Matlab. Finally, the obtained results confirm the performance of the optimization strategy.

\section{Data Availability}

The disciplinary data used to support the findings of this study have been deposited in the Network Repository (http://www.networkrepository.com).

\section{Conflicts of Interest}

The authors declare that they have no conflicts of interest.

\section{References}

[1] R. Antunes, Theoretical models of voting behaviour. sciences de la communication et des affaires, exedra No. 4, 2010.

[2] P. F. Lazarsfeld, B. Berelson, and H. Gaudet, The People's Choice: How The Voter Makes up His Mind in A Presidential Campaign, Columbia University Press, New York, USA, 1944.

[3] W. E. Miller and J. M. Shanks, The New American Voter, Harvard University Press, Cambridge, MA, USA, 1996.

[4] A. Downs, An Economic Theory of Democracy, Harper Collins Publishers, New York, USA, 1957.

[5] S. Abrams, T. Iversen, and D. Soskice, "Informal social networks and Rational Voting," British Journal of Political Science, vol. 41, no. 2, pp. 229-257, 2011.

[6] J. Bartle, S. Birch, and M. Skirmuntt, "The local roots of the participation gap: Inequality and voter turnout," Electoral Studies, vol. 48, pp. 30-44, 2017.

[7] S. Bartolini and P. Mair, Identity, Competition and Electoral Availability, Cambridge University Press, New York, USA, 1990.

[8] B. R. Berelson, P. F. Lazarsfeld, and W. N. Mcphee, Voting: A Study of Opinion Formation in a Presidential Campaign, Chicago University Press, Chicago, USA, 1954.
[9] A. Blais, To Vote or Not to Vote: The Merits And Limits of Rational Choice Theory, University of Pittsburg, Pittsburg, USA, 2000.

[10] M. Hoffman, G. León, and M. Lombardi, "Compulsory voting, turnout, and government spending: Evidence from Austria," Journal of Public Economics, vol. 145, pp. 103-115, 2017.

[11] M. Schelker and M. Schneiter, "The elasticity of voter turnout: Investing 85 cents per voter to increase voter turnout by 4 percent," Electoral Studies, vol. 49, pp. 65-74, 2017.

[12] A. S. Belenky and D. C. King, "A mathematical model for estimating the potential margin of state undecided voters for a candidate in a US Federal election," Mathematical and Computer Modelling, vol. 45, no. 5-6, pp. 585-593, 2007.

[13] K. Calderon, C. Orbe, A. Panjwani, D. M. Romero, C. KribsZaleta, and K. Ros-Soto, An Epidemiological Approach to The Spread of Political Third Parties, 2005, https://mtbi.asu.edu/ Sum\%20mer-2005.html.

[14] Q. J. A. Khan, "Hopf bifurcation in multiparty political systems with time delay in switching," Applied Mathematics Letters, vol. 13, no. 7, pp. 43-52, 2000.

[15] I. Petersen, "Stability of equilibria in multi-party political systems," Mathematical Social Sciences, vol. 21, no. 1, pp. 81-93, 1991.

[16] S. P. Sethi and G. L. Thompson, Optimal Control Theory: Applications to Management Science and Economics, Springer, New York, NY, USA, 2nd edition, 2000.

[17] A. Swierniak, U. Ledzewicz, and H. Schattler, "Optimal control for a class of compartmental models in cancer chemotherapy," International Journal of Applied Mathematics and Computer Science, vol. 13, no. 3, pp. 357-368, 2003.

[18] S. Wei, M. Zefran, and R. A. DeCarlo, "Optimal control of robotic systems with logical constraints: Application to UAV path planning," in Proceedings of the 2008 IEEE International Conference on Robotics and Automation (ICRA), IEEE, Pasadena, CA, USA, May 2008.

[19] D. Williamson, "Observation of bilinear systems with application to biological control," Automatica, vol. 13, no. 3, pp. 243254, 1977.

[20] J. Workman and S. Lenhart, Optimal Control Applied to Biological Models, Chapmal Hall/CRC, Boca Raton, Florida, USA, 2007.

[21] W. Ding, R. Hendon, B. Cathey, E. Lancaster, and R. Germick, "Discrete time optimal control applied to pest control problems," Involve, A Journal of Mathematics, vol. 7, no. 4, pp. 479489, 2014.

[22] D. C. Zhang and B. Shi, "Oscillation and global asymptotic stability in a discrete epidemic model," Journal of Mathematical Analysis and Applications, vol. 278, no. 1, pp. 194-202, 2003.

[23] Z. Hu, Z. Teng, and H. Jiang, "Stability analysis in a class of discrete SIRS epidemic models," Nonlinear Analysis: Real World Applications, vol. 13, no. 5, pp. 2017-2033, 2012.

[24] M. D. Rafal and W. F. Stevens, "Discrete dynamic optimization applied to on-line optimal control," AIChE Journal, vol. 14, no. 1, pp. 85-91, 1968.

[25] L. L. Cui, H. G. Zhang, D. Liu, and Y. S. Kim, "Constrained optimal control of affine nonlinear discrete-time systems using ghjb method," in Proceedings of the 2009 IEEE International Symposium on Adaptive Dynamic Programming and Reinforcement Learning, ADPRL 2009, pp. 16-21, Nashville, USA, April 2009.

[26] D. Liu, D. Wang, D. Zhao, Q. Wei, and N. Jin, "Neural-networkbased optimal control for a class of unknown discrete-time nonlinear systems using globalized dual heuristic programming," 
IEEE Transactions on Automation Science and Engineering, vol. 9, no. 3, pp. 628-634, 2012.

[27] V. Guibout and A. M. Bloch, "A discrete maximum principle for solving optimal control problems," in Proceedings of the 2004 43rd IEEE Conference on Decision and Control (CDC), vol. 2, pp. 1806-1811, 2004.

[28] C. L. Hwang and L. T. Fan, "A discrete version of Pontryagin's maximum principle," Operations Research, vol.15, no. 1, pp. 139146, 1967. 


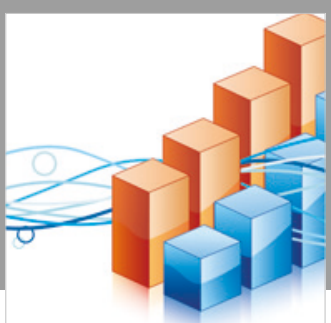

Advances in

Operations Research

\section{-n-m}
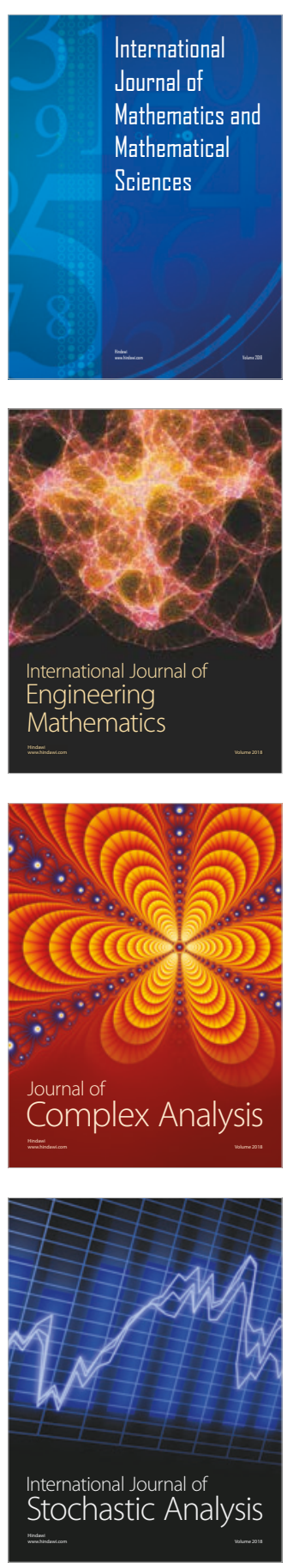
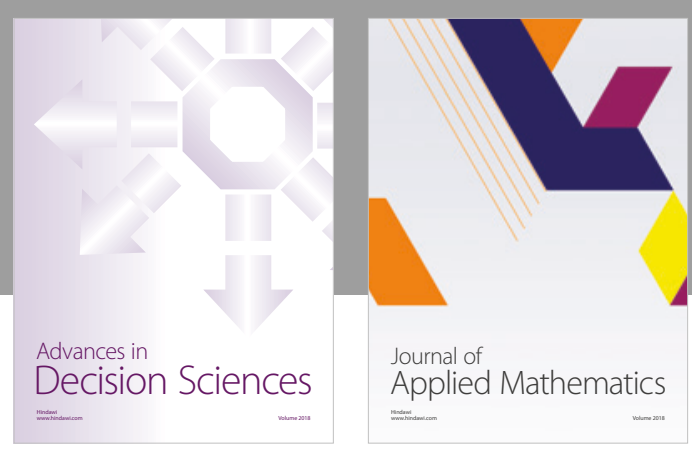

Journal of

Applied Mathematics
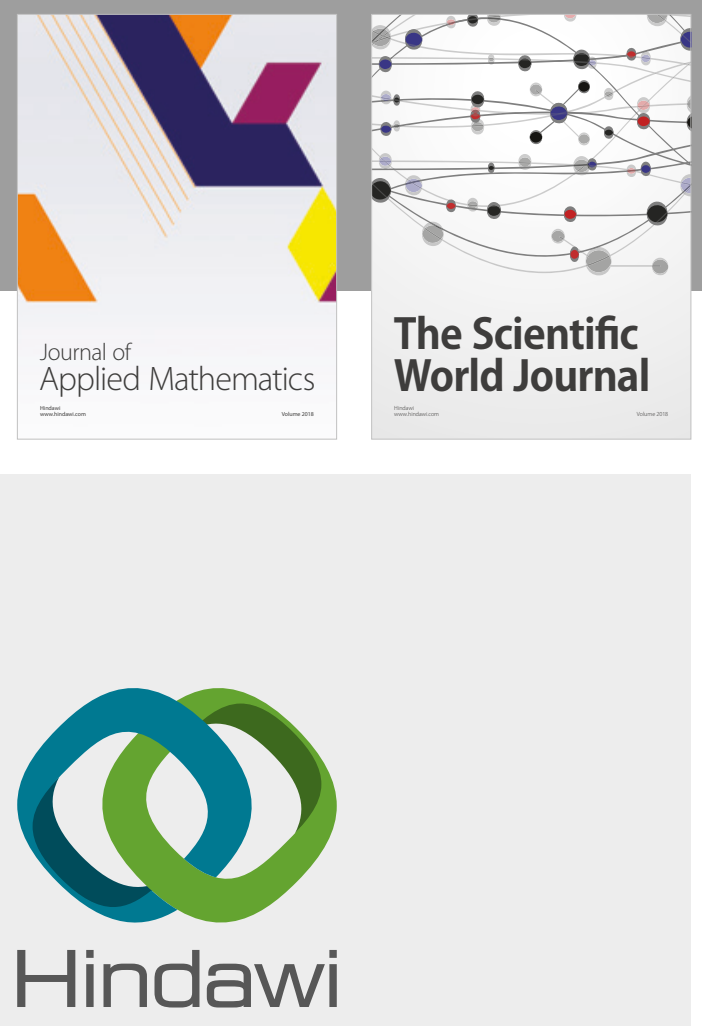

Submit your manuscripts at

www.hindawi.com

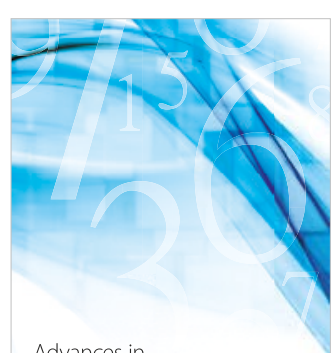

Advances in
Numerical Analysis
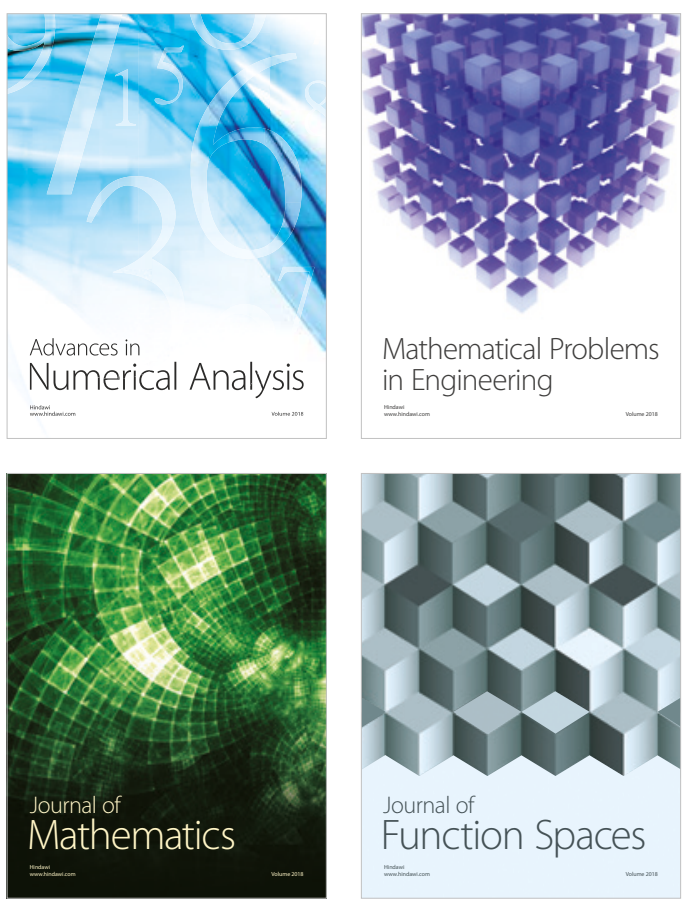

Mathematical Problems in Engineering

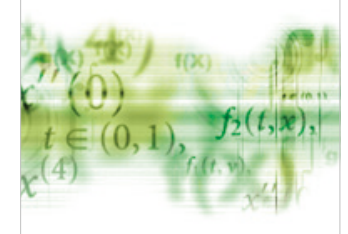

International Journal of

Differential Equations

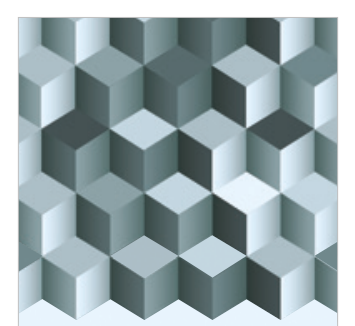

Journal of

Function Spaces

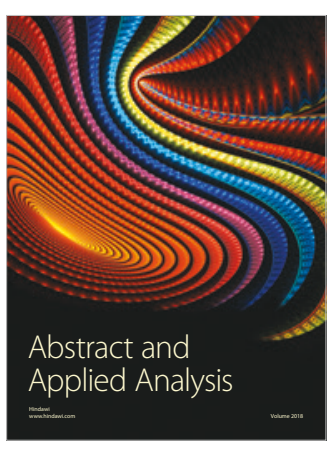

The Scientific

World Journal

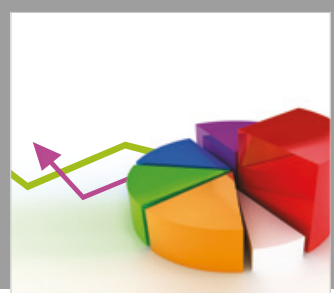

Journal of

Probability and Statistics
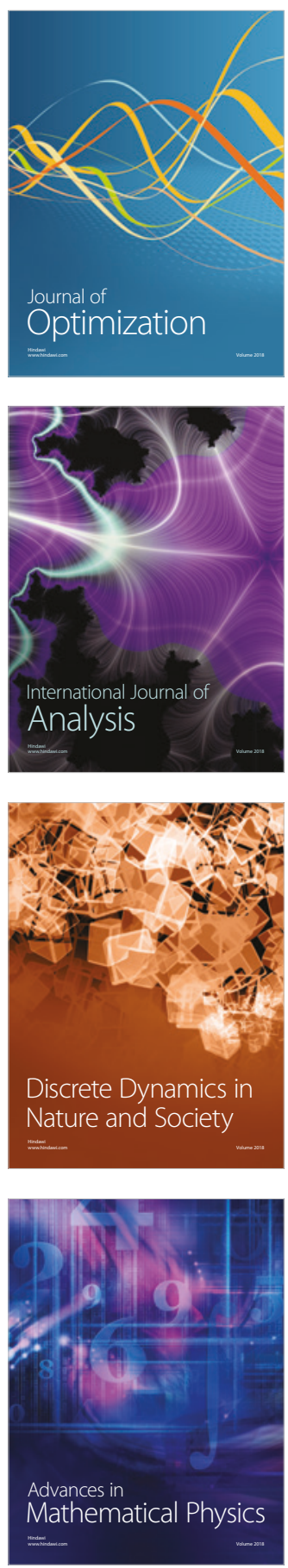